ARTICLE

\title{
A View of Beijing's Traffic Policy: Evaluation on the Policies Released in 2010 to Ease Traffic Congestion
}

\section{Xu Wang*}

Master of Public Policy and Management, Department of Asian and Policy Studies, The Education University of Hong Kong, Hong Kong, China

\begin{tabular}{|c|c|}
\hline ARTICLE INFO & ABSTRACT \\
\hline Article history & \multirow{6}{*}{$\begin{array}{l}\text { In today's society where the economy is developing rapidly and the process } \\
\text { of urbanization is accelerating, the traffic in major cities in China is facing } \\
\text { tremendous pressure. The economy of Beijing has developed rapidly, its } \\
\text { population is dense, the living standard of people has improved significant- } \\
\text { ly, and the number of cars has increased dramatically. From the end of } 2005 \\
\text { to the end of November } 2010 \text {, motor vehicles in Beijing increased from } \\
\text { about } 2.58 \text { million to about } 4.69 \text { million. The problem of traffic congestion } \\
\text { has become more prominent, affecting the daily lives of the residents. }\end{array}$} \\
\hline Received: 25 March 2021 & \\
\hline Accepted: 30 March 2021 & \\
\hline Published Online: 31 March 2021 & \\
\hline Keywords: & \\
\hline Traffic policy & \\
\hline
\end{tabular}

\section{Introduction}

\subsection{About the Policy}

In order to solve the problem of traffic congestion, in December 2010, The Beijing Municipal People's Government issued work opinions on further promoting the scientific development of the capital's transportation and intensifying efforts to alleviate traffic congestion, and introduced a series of policy measures, such as the implementation of traffic restrictions, the implementation of lottery purchase restrictions proposed for the first time in the whole country, the increased parking fees in central urban areas and so on.

\subsection{Purpose of the Report and the Methodology}

In this report, comparative analysis of specific data in several aspects, including changes in the congestion index of key road sections before and after the implementation of the Beijing policy, changes in car ownership, changes in the number of public parking lots and parking spaces, and changes in the structure of residents' travel mode will be conducted. This report will adopt comparative data analysis method to analyze and evaluate the effectiveness of the policy measures released by the government in 2010 and provide constructive suggestions on Beijing traffic congestion.

*Corresponding Author:

Xu Wang,

Master of Public Policy and Management, Department of Asian and Policy Studies, The Education University of Hong Kong, Hong Kong, China;

Email:wangxu202001@163.com 


\section{Background of the Policy}

\subsection{History of the Policy Intervention}

Before the promulgation of the traffic opinions in 2010, Beijing also issued other related policies. After 2000, the Beijing Municipal Government was committed to fully realize the strategic vision of "New Beijing, New Olympics". In order to build a modern international city with distinctive characteristics, a famous cultural city and a livable city, the government had done a lot optimizing its road infrastructure.

In 2007, the Beijing Municipal Party Committee and Municipal Government decided to compile the "Beijing Transportation Development Outline (2004-2020)", with the goal of initially establishing a national road transportation network by 2010 , optimize city roads, track systems, urban road systems, bicycle and pedestrian paths. Nevertheless, even with all the efforts, the problem of traffic congestion in Beijing was still serious.

For this reason, the Beijing Municipal Government has decided to introduce more effective measures and plans to promulgate the "Beijing's Opinions on Further Promoting the Scientific Development of the Capital's Transportation and Strengthening the Work to Alleviate Traffic Congestion." The Beijing Municipal Government launched a week-long solicitation of opinions. A total of 2,929 suggestions were received online, of which $94.2 \%$ offered constructive opinions and $5.8 \%$ opposed. After careful research and absorbing many valuable suggestions from citizens, this policy was promulgated on December 24, 2010.

\subsection{Problems It Seeks to Address}

The policy measures issued in 2010 are to solve a series of traffic problems in Beijing. For example, the functions of the central city and the high concentration of the population, the high-speed growth and high-intensity use of the number of motor vehicles, the insufficient attractiveness of public transportation, and the incompatibility of the comprehensive management level of the transportation with the excessively rapid growth of the number of motor vehicles. In response to these problems, the opinions on alleviating traffic congestion set the following goals. First, it is necessary to ensure that the traffic conditions in the central cities, especially the core areas, do not deteriorate, and it is possible to improve the traffic conditions on the main road sections to facilitate citizens' travel and ensure that the country provides strong traffic protection. Second, it is necessary to increase the proportion of residents traveling by public transportation. Significantly increase the proportion of public transportation in central cities, maintain the proportion of bicycle trips, and control the proportion of car trips. Third, reduce the emission of major pollutants from motor vehicles. Fourth, improve the level of road traffic safety and ensure the traffic safety of Beijing is at a leading level in China.

\subsection{Policy Instruments Adopted}

In order to achieve the above policy goals, various policies promulgated in 2010 adopted common government policy instruments, such as formulating traffic rules, charging road fees, increasing investment in road construction, increasing publicity of the environmentally-friendly travel mode. ${ }^{[1]}$

First, regarding the control of the number of motor vehicles, Beijing has implemented the policy for car purchase and taken measures to control the number of passenger cars. In accordance with the principles of openness, fairness and justice, to eligible enterprises, institutions, social organizations, legal persons and individuals, the allocation of passenger car allocation indicators will be free of charge by lottery.

Secondly, by issuing prohibitions, Beijing has also made a series of regulations to improve public transportation conditions, such as choosing to continue to implement and improve the rush hour regional traffic management measures. And continue to implement regional restrictions on motor vehicles during peak hours and regulations on yellow-label vehicles. In case of severe weather, major events, important festivals, etc., which may cause serious traffic congestion, take measures to drive motor vehicles on single and even numbers during peak hours on key traffic congestion sections.

In addition, users charges are adjusted: (1) Tolls are adopted to regulate public transportation, and the parking charging standards are reasonably adjusted. For example, the key areas within and outside the Third Ring Road are Class I areas, the areas within the Fifth Ring Road excluding Class I areas are Class II areas, and the areas outside the Fifth Ring Road are Class III areas, with parking on the roadside and open air outside the road. The parking price of parking and parking buildings (garages) is tiered, and the principle of charging prices for residential areas and night parking remains unchanged. (2) Formulate key congestion road sections or regional traffic congestion charging schemes, and implement them when appropriate.

At the same time, Beijing has also increased its funding to build a new generation of intelligent traffic management systems, improving the level of intelligent management. The construction funds for road traffic safety facilities and scientific and technological equipment of the whole city 
shall be borne by the municipal finance.

In addition, the government has increased its publicity efforts to the citizens and advocated low-carbon and environmentally-friendly travel through various media, such as the televisions and schools.

\section{Methodology}

\subsection{The evaluation Design}

In order to evaluate whether the policies introduced in 2010 effectively solve the problem of traffic congestion in Beijing, we selected different policy evaluation indicators to measure whether the number of private cars in Beijing is under control and whether public transportation has improved. These indicators are: changes in the congestion index of key road sections in a specific period before and after the implementation of the policy, changes in the number of road kilometers and bridges in Beijing after the policy is promulgated, changes in the number of public transportation lines, changes in the number of public parking lots and parking spaces Changes in the proportion of travel mode structure.

\subsection{Data Sources}

All our research data come from official government websites, such as Beijing Municipal Commission of Communications, Beijing Municipal Commission of Transportation Administration, Beijing Institute of Communications Development, and National Statistical Yearbook. After collecting various data in the years before and after the Beijing 2010 policy was promulgated, the data was re-edited using EXCEL spreadsheet software to form various charts.

\subsection{Statistical Methods}

The ultimate goal of data analysis is to evaluate the actual situation or the effectiveness of policy implementation. We use the simple before-after comparison method as the method of data statistics. Dynamic comparison refers to the comparison of index values in different periods under the same overall conditions, also called longitudinal comparison. We use this method to compare the differences in traffic data before and after the Beijing 2010 policy was issued to determine whether traffic congestion and car ownership have improved, and whether the policies that have been issued are effective. Specifically, by analyzing data such as personal car ownership, traffic congestion index, changes in the structure of transportation modes, changes in the number of highway bridges and road construction around 2010, it can be concluded whether this policy is implemented and whether it is to a certain extent
Controlled car ownership or improved traffic.

\section{Research Results}

\subsection{Increasing Public Transport Lines}

By searching for the Yearbook of Beijing in 2019, looking for the work of Beijing in road construction planning since 2005, this part analyzes the government's efforts to increase the number of road kilometers, bridges and public transport lines in Beijing and make some efforts to solve the problem of insufficient attractions of public transport for the citizens.

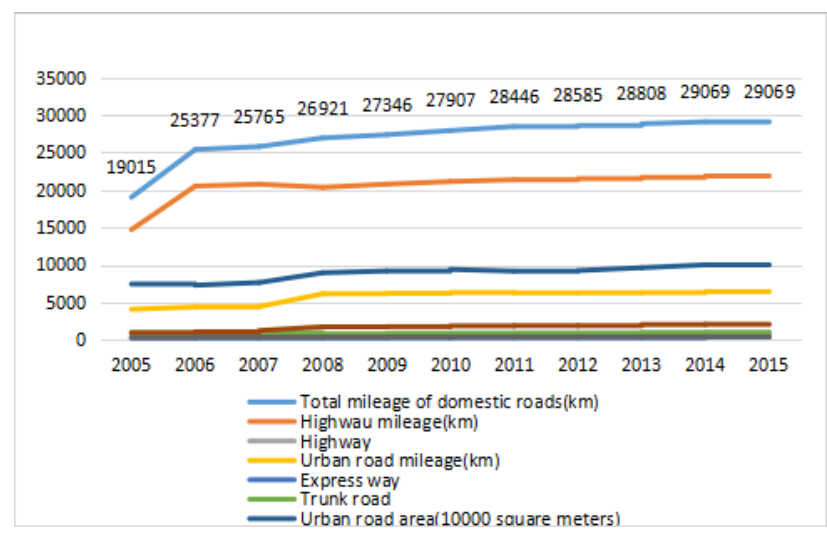

Chart 1. Changes of the amount of road $\mathrm{km}$ and bridges in Beijing

Data source: Beijng Municipal Commission of Transportation

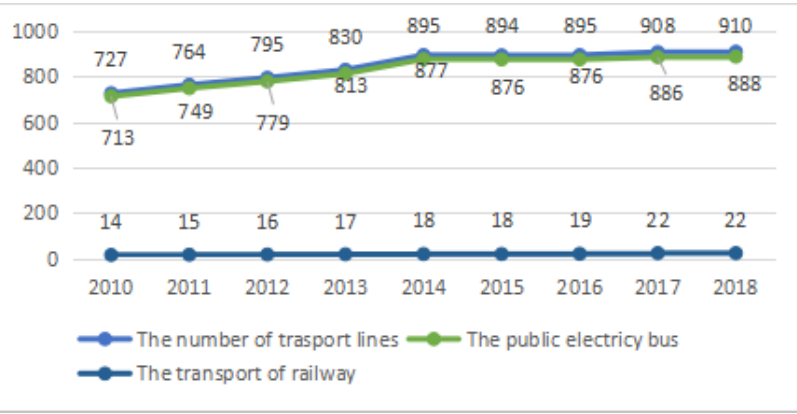

Chart 2. Changes in the number of public transport lines in Beijing

Data source: Beijng Municipal Commission of Transportation

By observing the growth trend of the total mileage of roads, the number of urban road bridges and overpasses between 2010 and 2015 in Table 1, it is not difficult to find that they all achieved a certain degree of growth. It is worth noting that due to the Olympic Games held in Beijing in 2008, this year's data can not be compared with the data of other years. These data represent that Beijing is constantly developing fast roads to alleviate traffic congestion in Beijing. The growth of these indicators means that the document "opinions on further promoting 
the scientific development of traffic in the capital and intensifying efforts to alleviate traffic congestion" issued in 2010 is being implemented. However, the resident population of Beijing is also increasing year by year, so it is impossible to determine whether the efforts of increasing road kilometers have effectively alleviated traffic congestion. As we all know, the development of public transport operation lines can not only make residents travel more convenient, but also reduce the number of times of people use private cars to travel, so as to reduce the occurrence of traffic congestion. Comparing the data of 2010 and 2018 in Table 2, we can find that these three data have increased significantly, indicating that the documents issued by Beijing in 2010 have been implemented.

\subsection{The Number of the Parking Lots}

By searching for the official website data of Beijing Municipal Transportation Committee, this paper finds out that the changes in the number of public parking lots and parking spaces in Beijing since 2009, 2010 and 2017, and then verifies whether this measure has achieved certain effects by using the Beijing traffic congestion index since 2010 .

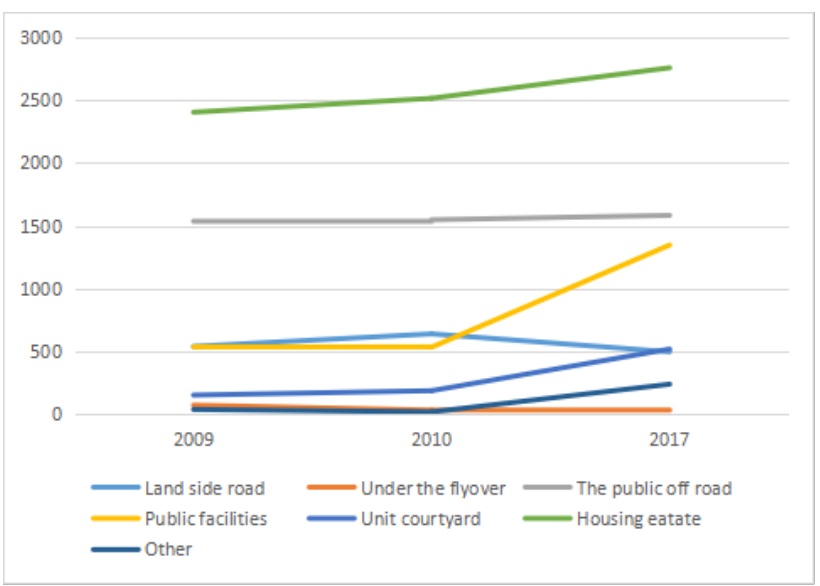

Chart 3. The public parking lots in Beijing

Data source: Beijing Municipal Commission of Transportation

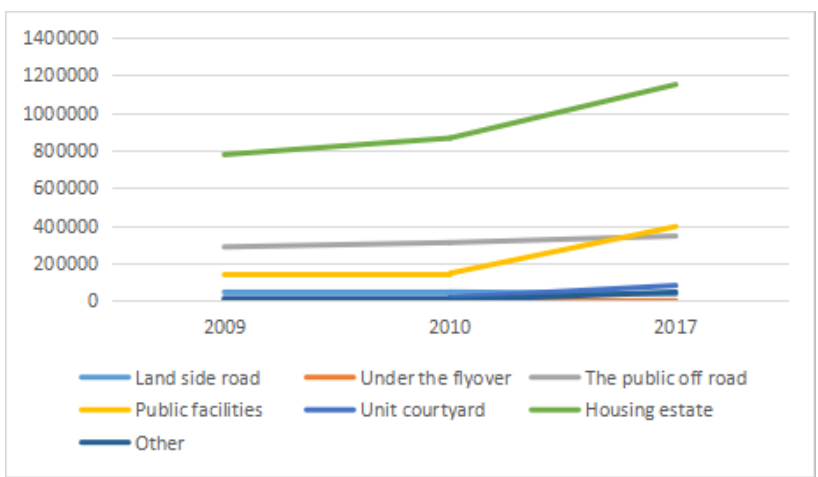

Chart 4. The public parking spaces in Beijing

Data source: Beijing Municipal Commission of Transportation
An important solution to alleviate traffic congestion is to provide sufficient parking spaces to reduce traffic congestion caused by disorderly parking the motor vehicles, and finally achieve the policy goal of reducing traffic congestion. We will analyze the data of parking lots and parking spaces in Beijing in 2010 and 2018 to prove that providing sufficient parking spaces can effectively alleviate traffic congestion.

Compared with the number of parking lots and parking spaces, the number of parking lots and parking spaces in Beijing in 2017 increased significantly compared with that in 2010. In terms of the number of parking spaces and lots, residential areas are the largest number of parking lots and parking spaces in Beijing, and they showed an increasing trend. However, the parking lots and parking spaces under the landside road and overpass are decreasing. It is not difficult to understand that if the driver does not park the car correctly, it will make it difficult for other drivers to pass the land side road and overpass, which is extremely easy to cause traffic congestion.

From the chart of Beijing road congestion index, we can see that the road congestion index in 2018 has decreased compared with the 2010 road congestion index. Therefore, increasing the number of car park and the number of parking spaces and increasing public transport lines will play a positive role in reducing traffic congestion.

\subsection{The Structure of Travel Mode}

\subsubsection{Proportion of Residents' Travel Mode Structure}

The proportion of public transportation used by residents in transportation is an important basis for measuring the policy factor of increasing the proportion of public transportation trips. Public transportation is an important foundation for the overall environment of Beijing. Prioritizing the development of public transportation is an inevitable requirement for the continuous development of population and economy. Reducing the total number of vehicles in the central area of the city and increasing the capacity of individual public transport participants are important measures to improve the efficiency of Beijing's transportation resource utilization and alleviate traffic congestion.

According to the annual traffic report and the classification rules of the main means of transportation, we divide the residents' transportation modes into six categories: cars, buses, subways, taxis, bicycles and others for data collection, processing, and display discussions. 
We found the annual reports of Beijing's transportation development through the official website of Beijing Transportation Development Institute. Under the topic of residents' travel characteristics, search for data on residents' travel patterns during the eight years from 2006 to 2014, manually input the data into Excel, and display the processed data results with a percentage stacked column chart (Chart 5).We adopt the Simple before-after comparison method to compare the transportation modes of Beijing residents before and after the implementation of the policy (from 2006 to 2014) to judge the policy factor of increasing the proportion of public transportation.

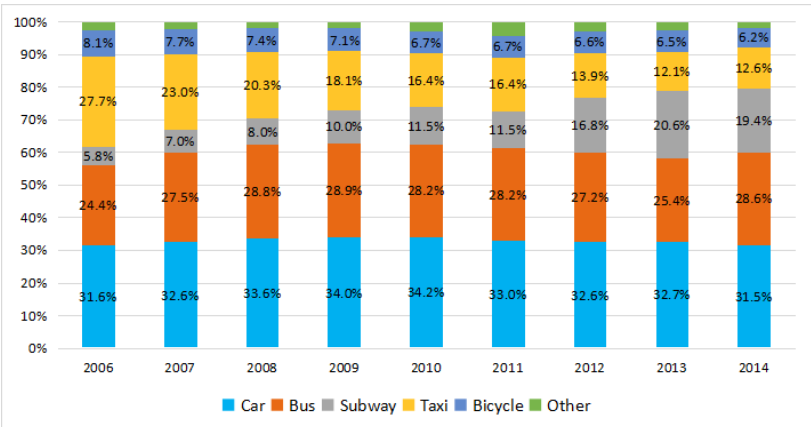

Chart 5. Stacked histogram of the percentage of residents' transportation modes in Beijing from 2006 to 2014

Data source: Beijing Transportation Development Research Institute

From the stacked histogram of the percentage of residents' transportation modes in Beijing from 2006 to 2014, we found that cars accounted for the largest proportion of Beijing residents' transportation trips. Although the overall decline has occurred, the proportion is very small, only $0.1 \%$. The data show that the largest decline was from 2010 to 2011. The results may be more obvious due to private car restrictions such as lottery and traffic restrictions, but the decline was not large in the later period and still accounted for the largest proportion.

At the same time, with urban population growth and economic growth, the proportion of using bicycles to go out is getting smaller and smaller, which also shows the inconvenience of bicycles as a daily transportation tool in Beijing. Among the key public transportation in this section, subways and buses are the two main forms of public transportation. According to the data of Beijing Transportation Development Research Institute, we found that although the total number of people who choose public transportation to travel has increased, overall shows an upward trend, but the fluctuations are not large and the growth rate is small.And in 2007, $27.5 \%$ of Beijing residents chose public transport as their mode of transportation, while in 2013, it accounted for only $25.4 \%$.
On the other hand, the subway, a public transportation vehicle, accounted for an increase of $13.6 \%$ in the eight years from 2006 to 2014. Although it is not the largest of the six types of transportation, it is becoming more and more important. To implement the policy goals, we have made great efforts on the subway track tools. From the data, the implementation of the policy goal of increasing the proportion of public transport trips is still relatively effective.

\subsubsection{Track Construction}

Public transportation and subway are two important types of public transportation. Compared with public transportation, subway has greater advantages. Taking the subway is not only faster, more comfortable, safe, green and environmentally friendly, but also saves land. More importantly, the subway does not occupy ground roads, which can alleviate traffic congestion to a greater extent. It has a larger carrying capacity and can transport more passengers one way.In first-tier cities such as Beijing, subways play a greater role in public transportation than buses. Therefore, we conduct data collection and research on the construction and investment of subway tracks. The rail transit network mainly includes five indicators: rail transit operating vehicles, number of operating lines, operating line length, mileage, and annual passenger volume.

Through the official website of the Transportation Management Bureau of the Beijing Municipal Commission of Transportation, we found the data corresponding to the operation indicators of the subway rail transit network from 2007 to 2013, and made the data into a table (Table 1) and a line chart (Figure 6) to analyze and determine the policy After implementation, whether the policy goal of increasing the proportion of public transport trips has been effectively achieved.

Table 1. Comparison of operation indicators of Beijing rail transit network from 2007 to 2013

\begin{tabular}{ccccccccc}
\hline & Year & $\mathbf{2 0 0 7}$ & $\mathbf{2 0 0 8}$ & $\mathbf{2 0 0 9}$ & $\mathbf{2 0 1 0}$ & $\mathbf{2 0 1 1}$ & $\mathbf{2 0 1 2}$ & $\mathbf{2 0 1 3}$ \\
\hline $\begin{array}{c}\text { Rail transit operating vehi- } \\
\text { cles (vehicles) }\end{array}$ & 1130 & 1714 & 2014 & 2463 & 2850 & 3685 & 3998 \\
$\begin{array}{c}\text { Number of operating lines } \\
\text { (items) }\end{array}$ & 5 & 8 & 9 & 14 & 15 & 16 & 17 \\
$\begin{array}{c}\text { Operating line length (km) } \\
\begin{array}{c}\text { Driving mileage } \\
\text { (ten thousand vehicle } \\
\text { kilometers) }\end{array}\end{array}$ & 142 & 200 & 228 & 336 & 372 & 442 & 465 \\
\hline
\end{tabular}

Data source: Beijing Municipal Transportation Administration Bureau 


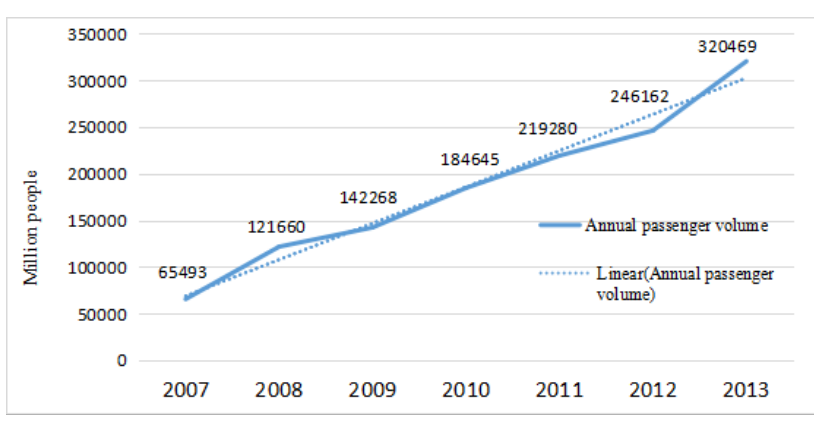

Chart 6. Line chart of annual passenger traffic of Beijing subway from 2007 to 2013

Data source: Beijing Municipal Transportation Administration Bureau

From Table 1 and Chart 6, we can find that the development of rail transit from 2007 to 2013 is very impressive. Among them, the number of operating vehicles of rail transit has increased year by year, and the number of operating routes has increased by 12 , and the length of operating routes and mileage have also been significantly changed in 2011, indicating that the implementation of the 2010 transportation policy is very effective of.

Through the line chart of the annual passenger traffic of Beijing Metro from 2007 to 2013, it can be seen that the annual passenger traffic has been increasing linearly at a high speed, and the passenger traffic has successfully exceeded 2 billion passengers in 2011. From the objective data of Beijing subway rail passenger traffic, we can analyze our It is found that the development of public transportation has achieved remarkable results with the support of policies, which can alleviate traffic congestion to a certain extent.

\subsubsection{Traffic Congestion Index}

By analyzing the changes of the congestion index of key sections, the measures in 2010 basically achieved the policy objectives of ensuring the traffic condition of the core area does not deteriorate and improving the traffic condition of major sections. Traffic congestion refers to the phenomenon that the speed and efficiency of motor vehicles on the road network are reduced due to the contradiction between supply and demand of traffic volume, or due to the influence of weather, construction, traffic events, traffic control and other factors. Road congestion generally has the following three manifestations:

(1) Low speed vehicles or frequent stops on various parts of highways, such as urban expressways with speeds of less than $40 \mathrm{~km} / \mathrm{h}$, main roads and secondary roads with speeds of less than $25 \mathrm{~km} / \mathrm{h}$;

(2) In the usual running phase, the vehicle is unable to move forward for more than 5 minutes after queuing in place;
(3) Vehicles wait for three green lights at an intersection operated by signals but fail to pass, pedestrians and cyclists wait for two green lights but fail to pass.

The evaluation Index system of road Traffic operation in Beijing, adopted when average travel speed as the Traffic running status hierarchy Index (Table 2), and adopted the congestion Index (also called Traffic Index, Traffic Performance Index TPI) as a comprehensive Index reflecting road network flow or congestion degree of conceptual, daily Traffic congestion Index classification as shown in Table 3.

Table 2. Traffic operation grade division based on average travel speed of section

\begin{tabular}{cccccc}
\hline $\begin{array}{c}\text { Traffic operational } \\
\text { level }\end{array}$ & Blocked & $\begin{array}{c}\text { Basically } \\
\text { unblocked }\end{array}$ & $\begin{array}{c}\text { Light } \\
\text { congestion }\end{array}$ & $\begin{array}{c}\text { Moderate } \\
\text { congestion }\end{array}$ & $\begin{array}{c}\text { Severe } \\
\text { conges- } \\
\text { tion }\end{array}$ \\
\hline Expressway & $\mathrm{V}>65$ & $50<\mathrm{V} \leq 65$ & $35<\mathrm{V} \leq 50$ & $20<\mathrm{V} \leq 35$ & $\mathrm{~V} \leq 20$ \\
$\begin{array}{c}\text { Arterial road } \\
\text { Secondary road, } \\
\text { branch road }\end{array}$ & $\mathrm{V}>40$ & $50<\mathrm{V} \leq 65$ & $20<\mathrm{V} \leq 30$ & $15<\mathrm{V} \leq 20$ & $\mathrm{~V} \leq 15$ \\
\hline
\end{tabular}

Note: $\mathrm{V}$ represents the average shape travel speed of section $(\mathrm{km} / \mathrm{h})$

Data source: Beijing Institute of Transportation Development

Table 3. Analysis of daily traffic congestion index

\begin{tabular}{cccccc}
\hline $\begin{array}{c}\text { Daily Traffic } \\
\text { congestion index }\end{array}$ & {$[\mathbf{0 , 2}]$} & $\mathbf{( 2 , 4 ]}$ & $\mathbf{( 4 , 6 ]}$ & $\mathbf{( 6 , 8 ]}$ & $\mathbf{( 8 , 1 0 ]}$ \\
\hline $\begin{array}{c}\text { Congestion levels } \\
\text { on the road net- } \\
\text { work }\end{array}$ & Blocked & $\begin{array}{c}\text { Basically } \\
\text { un- } \\
\text { blocked }\end{array}$ & $\begin{array}{c}\text { Light con- } \\
\text { gestion }\end{array}$ & $\begin{array}{c}\text { Moderate } \\
\text { conges- } \\
\text { tion }\end{array}$ & $\begin{array}{c}\text { Severe } \\
\text { conges- } \\
\text { tion }\end{array}$ \\
\hline
\end{tabular}

Data source: Beijing Institute of Transportation Development

According to the statistical results shown in Chart 7, the average traffic congestion index of the whole Beijing road network during peak hours in 2019 is 5.48, a slight decrease $(1.08 \%)$ compared with the 5.54 index of the previous year, which is classified as "light congestion".

The average morning peak traffic index is 5.08, and the average evening peak traffic index is 5.88. The evening peak traffic congestion degree is higher than the morning peak, with an increase of $-0.39 \%$ and $-0.02 \%$ respectively from 2018. According to the daily traffic congestion index rating standard, the morning and evening peak traffic is at the level of mild congestion and moderate congestion.

The average daily congestion time (moderate congestion and severe congestion) was $3 \mathrm{hrs}$ in total, 5 mins less than that in 2018.

The morning rush hour congested roads are mainly in the north-south direction of the ring road and the main contact lines in the direction of Entering Beijing, while the evening rush hour congested roads are mainly in the north-south direction of the ring road and the main passageways in the direction of leaving the city. The chart below shows the annual 
traffic index of Beijing from 2007 to 2019.

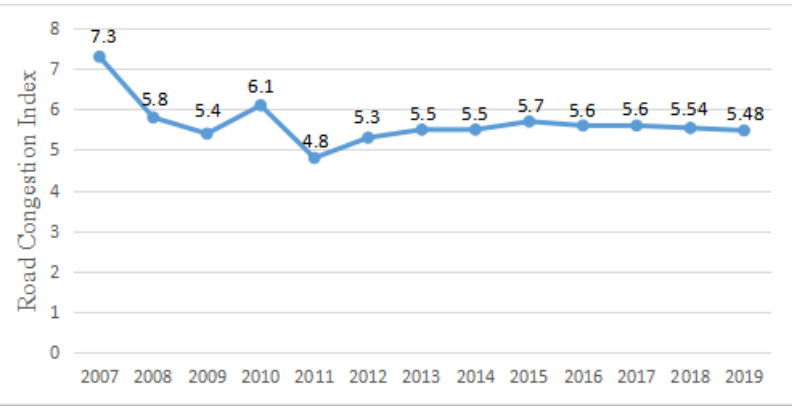

Chart 7. Annual Traffic Index of Beijing from 2007 to 2019

Data source: Beijing Institute of Transportation Development

The traffic congestion index fell dramatically after the implementation of the lottery car purchasing scheme in early 2011, as can be seen from the split line chart of Beijing's annual traffic index from 2007 to 2019 . It demonstrates that the control of the policy of restricting car purchases is real and effective. The problem of more cars on the road can be addressed from the root by controlling the rate of private car ownership, thereby alleviating the problem of traffic congestion.Although the traffic congestion index dropped sharply in 2011 due to policy factors, it recovered slowly from 2012 to 2015. After 2015, the traffic congestion index declined year by year. From the overall trend of the data, it can be seen that the implementation of the traffic policy has been effective. The overall traffic congestion index has decreased significantly compared with that before 2010, and the traffic operation tends to be good on the whole.

However, it can be seen from the ups and downs of the data that the policy implementation has the characteristics of temporary and chronic mitigation of traffic conditions, and its persistence is insufficient and the effect is relatively small. About whether the policy clearly solved some congestion doesn't give a definite answer, traffic congestion is affected by many factors, such as the traffic accident causes the short road congestion, roadway taking-up construction can lead to local traffic blocked, the bad weather will affect traffic capacity and so on, these can't directly from the congestion index, the index of Beijing concluded that still need to combine various data analysis.

\subsubsection{Ownership of Vehicles}

Beijing's central location, the high population concentration, the rapid rise in the number of motor vehicles and the high intensity of road usage have made Beijing 's traffic development face a serious situation. In response to this situation, the government has released a variety of administrative intervention policies to manage traffic congestion in Beijing, such as increasing the standard of parking fees, introducing the last-number traffic restriction policy, setting up the last-number traffic reduction policy,setting up bus lanes and so on.

In order to control the total number of motor vehicles in Beijing and alleviate the current situation of traffic congestion in Beijing, the much-concerned measures to alleviate traffic congestion in Beijing "Interim Provisions on The Regulation and Control of The Number of Passenger Cars in Beijing" and its implementation rules were launched on December 23, 2010, and the implementation rules are stipulated: In the future, Beijing will allocate an average of 20,000 vehicles per month through a lottery, with individuals accounting for 88 percent of the total, and each driver will be limited to one car. Vehicle registration is required to obtain vehicle configuration indicators through the "lottery" program.

According to estimates, by the end of 2011, the number of motor vehicles in Beijing was 4,983 m, 174,000 more than that of 2010, up 3.6 percent, due to the effect of regulatory and control policies on passenger cars. In Beijing, the number of motor vehicles was 5.20.0 million by the end of 2012, a rise of 217,000 or 4.4 percent over 2011. The progress has since shown a pattern of approximately exponential growth. In 2019, the number of motor vehicles in Beijing reached 6.365 million, 281,000 more than that of the previous year. Among them, the number of private motor vehicles reached 5.13 million, an increase of 236,000 over the previous year.

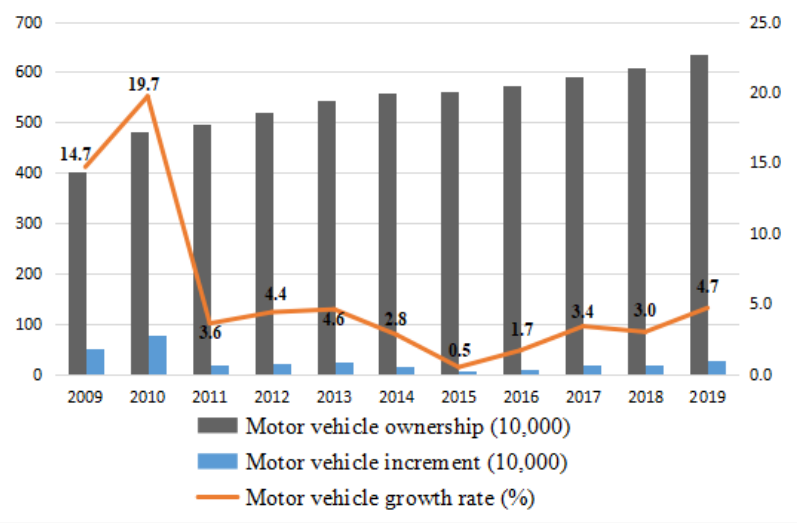

Chart 8. Chart of Motor Vehicle ownership and Incremental Change in Beijing from 2009 to $2019^{[2]}$

By comparing the above-mentioned net increase and growth rate, it can be found that Beijing's motor vehicle ownership growth trend has been higher than 10 percent since 2009 and is on the rise.However, the growth rate of vehicle ownership in Beijing has been substantially kept back since the implementation of the registration lottery scheme at the end of 2010, dropping from 19.7 percent to 3.6 percent, and the growth rate has since slowed down. It also proves that Beijing's car-lottery policy has limited the natural growth of the number of vehicles.

After the introduction of the 'car buying lottery' policy in 
January 2011, the net increase in motor vehicles in Beijing in 2011 was 617,000 less than in 2010, effectively curbing the rapid growth of motor vehicles and to some extent alleviating the excessive traffic congestion in Beijing. The alleviation of traffic congestion does not mean the lottery scheme is going to die out. Beijing has a large number of motor vehicles, if it does not carry out certain "administrative control", then the traffic congestion is bound to be more serious. At a time when the pace of public transport construction is not keeping pace with the growth of private cars, policies that restrict car purchases in the short term could help prevent traffic congestion from worsening. Therefore, the continuous "lottery car" has its practical significance.

\section{Conclusions}

To sum up, we find that the development of public transport has a significant effect under the support of policies, which can alleviate traffic congestion to a certain extent. In the meantime, the implementation of the policy of increasing the proportion of public transport trips is more effective. At the same time, increasing the number of parking lots and parking spaces, and increasing public transport lines can help to reduce traffic congestion. In addition, the provision of sufficient parking spaces can effectively alleviate the traffic congestion, and the rapid growth of motor vehicles was effectively curbed, which alleviated the traffic congestion to a certain extent in Beijing. Generally speaking, the measures released in 2010 have contributed to the prevention and control of traffic congestion in Beijing to a certain extent.

As many scholars believed, the rapid urbanization leads to the problem of urban traffic congestion. There is no specific way to solve the problem of traffic congestion around the world. However, a universal governance framework can be proposed. Each city can control traffic congestion within the framework and make some adjustments. ${ }^{[3]}$ (Mahmoud Hassan, 2013) The same is true of Beijing's traffic congestion. The root causes of the problem still exists, and the congestion problem has not been fundamentally and significantly improved. This is the reason why Beijing put forward various supplementary policies, such as relieving non capital functions, to solve the problem of congestion from the root.

We believe that Beijing can make more efforts in several aspects:

Firstly, we should speed up the process of relieving Beijing's non capital functions. The urban polycentric theory advocates that the population should be scattered around rather than gathered in the central business district, and the residents' work and living areas should be transferred outside the central area. For example, in Shanghai, from 1990 to 2000, Shanghai's sub centers developed from two sub centers to six sub centers, and the population showed a trend of diffusion.
In 2009, Wang Hongxia took Shanghai as a case. ${ }^{[4]}$ Through research and analysis, she found that through years of efforts to form a multi-center layout and four level urban system, Shanghai has developed into a multi-center mode, which is an important reason why Shanghai has a large population and developed economy, but its traffic has not reached a moderate degree of congestion. Beijing can speed up the construction of the sub center, and make the new central area more attractive than the existing urban center, with more perfect functions, higher quality and better ecological environment. ${ }^{[5]}$

Secondly, we will implement the policy of collecting traffic congestion charges. In 2010, the traffic congestion charge was stipulated to be implemented on an optional basis, but it has not been widely implemented due to various considerations. ${ }^{[6]}$ Beijing needs to improve its traffic information management system and combine congestion charges with the government's travel incentive policies. For example, when congestion charges reach a certain amount, they can get free travel time cards of public transport, and encourage paying car owners to choose public transport mode.

Thirdly, we will increase the charges for underground parking lots in large consumption centers and CBD business centers.

It will take a long time to improve the traffic congestion in Beijing. Any policy intervention will not be immediate, so residents may not feel the obvious policy impact. However, as long as we start from the root causes and draw lessons from the world's experience reasonably, we will surely have a great improvement.

\section{References}

[1] Talukdar, M. H. (2013). Framework for traffic congestion management. Economia. Seria Management, 16(1), 54-64.

[2] Zhang Fan. (2014). Research on the impact of car lottery policy on Beijing's motor vehicle ownership. Xiamen Science and Technology, (1), 57-62.

[3] Mahmud Hassan. Framework for Traffic Congestion Management $[\mathrm{J}]$. Economia: Seria Management, 2013, (06) : 54-65.

[4] Wang Hongxia. (2009). Urban system construction in the process of multi-centered spatial evolution: A study of Shanghai as an example. Shanghai Economic Research, (1), 13-22.

[5] Wu Di. (2016). Research on Traffic Congestion in Beijing and Countermeasures (Master's thesis, Minzu University of China).

[6] Fan Wei. (2016). Research on the Causes of Traffic Congestion in Beijing and Government Governance Countermeasures (Master's thesis, University of International Business and Economics). 